\title{
Interventions for Teaching Sketching Skills and Reducing Inhibition for Novice Engineering Designers
}

\author{
Joran W. Booth, Elkin A. Taborda ${ }^{l}$, Karthik Ramani, and Tahira Reid,
}

The C-Design Lab and the REID Lab, Department of Mechanical Engineering, Purdue University, 585 Purdue Mall, West Lafayette, IN, 47906, USA

\begin{abstract}
This paper explores improving sketching skills and reducing the inhibition to sketch for student designers. In the first study, students were taught sketching skills through an in-class workshop. The effect was evaluated using a pre-midpost test $(n=40)$. In the second study, students were led through art activities to reduce their inhibition to sketch. The effect was tested using another pre-midpost test $(n=26)$. The first study found sketching skills increased, but declined with disuse. The second study found reduced inhibition immediately after the workshop, an increase after the sketch skills workshop, and a decrease over the semester. This suggests that sketch training and inhibition-reducing exercises are effective in the short term, but must be emphasized over time for a permanent change.
\end{abstract}

Keywords:

Drawing, Design tools, Design education, Creativity, Sketch Inhibition

Corresponding Author: Joran W. Booth, boothj@purdue.edu, 1-765-494-7209

${ }^{1}$ Present Address: La Escuela de Ingeniería Mecanica, Universidad Pontifica

Bolivariana, Medellin, Colombia 


\title{
Interventions for Teaching Sketching Skills and Reducing Inhibition for Novice Engineering Designers
}

\begin{abstract}
This paper explores improving sketching skills and reducing the inhibition to sketch for student designers. In the first study, students were taught sketching skills through an in-class workshop. The effect was evaluated using a pre-midpost test $(n=40)$. In the second study, students were led through art activities to reduce their inhibition to sketch. The effect was tested using another pre-midpost test ( $n=26)$. The first study found sketching skills increased, but declined with disuse. The second study found reduced inhibition immediately after the workshop, an increase after the sketch skills workshop, and a decrease over the semester. This suggests that sketch training and inhibition-reducing exercises are effective in the short term, but must be emphasized over time for a permanent change.
\end{abstract}

Keywords:

Drawing, Design tools, Design education, Creativity, Sketch Inhibition

Visual representations are an integral part of the design process (Buxton, 2007; McKim, 1980; Goldschmidt, 1991). Expert designers create visualizations and rapidly shift between design tasks, particularly during the problem generation stage (Cross, 2004; Atman et al., 2007). During ideation, freehand sketching helps designers handle different levels of abstraction (Goldschmidt, 1991; Cross, 1999), think through problems (Cross, 1999; Buxton, 2007), understand illdefined problems (Cross, 1989), extend short-term memory for problem-solving (Ullman, 2003; Schutze et al., 2003), and aid communication and team building (Goldschmidt, 2007). Sketches, as opposed to drawings or illustrations (Pei et al., 2011), have the characteristics of being disposable, rapid, vague, subject to 
reinterpretation, and include only enough information to communicate an idea, but not more (Buxton, 2007; Tovey et al., 2003; Rodgers et al., 2000). Because of these elements, sketches are often unintelligible outside the original context in which they were drawn (Buxton, 2007).

While researchers know that visualization is important in design, few engineering design curricula teach ambiguous, freehand sketching as a tool for design thinking (Ullman et al., 1990; Ferguson, 1992; Linsey et al., 2011). Many institutions treat freehand sketching as unnecessary and only teach it to emphasize the principles of engineering drawing and CAD (Duff \& Ross, 1995; Mohler, 2008). Perhaps due to the lack of sketch training, CAD is being used earlier in the design process. However, the early use of CAD leads to circumscribed thinking, premature fixation, and bounded ideation (Robertson \& Radcliffe, 2009; Lawson, 2002; Yang, 2005; Walther et al., 2007). Therefore, there is a need to reintroduce freehand sketching in design education (Ullman et al., 1990). A few efforts in engineering have already been made in this area, and we propose two interventions that build on these. In this paper, we describe past efforts and motivations for sketch training, and propose and test a pedagogical approach to encourage design thinking through the use of sketching, prior to the use of CAD in detailed design. We also describe and test a set of art-based interventions designed to reduce student inhibition to sketch. We test these techniques in a toy design course, and report our preliminary outcomes.

\section{Background}

Sketching has been frequently studied in design (Dinar et al., 2014). Freehand sketching improves the quality and novelty of ideas (McKoy et al., 2001) and the quantity of ideas (Hernandez et al., 2012). It is not certain if sketching correlates with the quality of the final design (Song \& Agogino, 2004), or not (Yang \& Cham, 2007; Yang, 2009). Ideas communicated with high-quality sketches are much more likely to be perceived as creative compared with the same ideas shown with low-quality sketches (Kudrowitz et al., 2012). This gives a good sketcher an advantage over other designers. It has also been found that 
sketching is most effective when paired with other forms of communication, such as annotations, verbal communication, or hand gestures (Song \& Agogino, 2004; Yang, 2009; Adler \& Davis, 2007; Purcell \& Gero, 1998). While each of these media is important, sketching is suggested to be the most important for ideation (McKoy et al., 2001; Linsey et al., 2011). As a result, some proposed ideation techniques are built solely on the principle of sketching (e.g. "brainsketching" (van der Lugt, 2002)). While many studies have explored the effect of sketching, virtually none of these have trained their participants in freehand sketching prior to the study. At first glance, it may seem trivial to train students to sketch, especially since it is so informal (Buxton, 2007). However, when we look at the history of art, we find that the skills for sketching have taken a long time to develop. For example, perspective drawing was so nonintuitive that our modern version was only re-discovered after 1000 years, and then only by unusual means. Spatial depth was known in Grecian and Roman art (e.g. in Pompeii (Curran, 1988)), but these techniques were lost. When realism came back into fashion in the Renaissance, artists struggled for centuries to identify a viable system for perspective. Giotto proposed a systematic method based on algebra; however it was not fully convincing (Payne, 2012). Only in 1413 was it rediscovered. Brunelleschi painted a scene on a mirror and discovered after that the lines of the painting converged to a similar point on the horizon (Payne, 2012). In hindsight, it seems obvious that vanishing points on a horizon would lead to perspective, but the history only serves to underscore the non-intuitive nature of it. Similarly, mastery of other sketching skills requires training and practice.

\subsection{Factors that Inhibit Sketching}

While sketching is important, many studies have noted that design students are reluctant to sketch. We define this reluctance as "inhibition". We gathered various studies that describe a reluctance to sketch and categorized them into different sources of inhibition. We also defined one type based on our own inclass experiences. The effect of these factors is that they tend to cause high 
cognitive load, which load is correlated with lower creative output (Martindale, 1999). This effect is undesirable when generating concepts.

- Personal inhibition - trying to make the sketch too perfect on the first try, or become preoccupied with the mechanics of sketching or drawing (Pable, 2008).

- Intellectual inhibition - the belief that sketching is not relevant to engineering or design, or ignorance of its importance (Schmidt et al., 2012).

- Skill-set inhibition - a perceived or real deficiency in skill that can be addressed by training or practice (Richards, 2013; Yang and Cham, 2007).

- Social inhibition - the fear of being unfavorably judged by others (Farzaneh et al., 2012), as related to the fear of public speaking (Rattine Flaherty, 2014).

- Social loafing and matching - when group participants try to minimize their contribution to the group (Farzaneh et al., 2012), and therefore do not sketch.

- Situational inhibition - when a sketcher is not in a proper state of mind to allow the "flow of consciousness" or "feeling" of the sketch (Garner, 1990).

- Technological inhibition - a greater interest in digital visualizations, especially 3-D ones, than analog 2-D ones (Oehlberg et al., 2009)

- (Based on in-class observations) Comparative inhibition - caused by the presence of a superior sketcher or recent exposure to a high-quality sketch or drawing.

\subsection{Interventions for Teaching Sketching Skills and Reducing Inhibition}

Sketching skills interventions have varying emphases, such as product sketching (van Passel \& Eggink, 2013), free-hand technical drawing (Jacobs \& Brown, 2004), and visual thinking (Lane et al., 2010). Architecture and industrial design, teach freehand sketching as a means for problem solving, idea generation and concept generation (Bilda et al., 2006; Eissen \& Steur, 2011). 
While prior researchers have proposed interventions for teaching sketching, few have explored interventions to reduce inhibition to it. Prior efforts include requiring students to sketch as a part of homework assignments (Schmidt et al., 2012; Grenier, 2008; Ruocco et al., 2009). Others encouraged sketching through the use of analog-to-digital technology (Leake \& Weightman, 2011) or electronic interfaces (Chandrasegaran et al., 2014). To the best of our knowledge, only one engineering study has used a method to reduce inhibition, where they required participants to draw a dream house prior to a concept generation activity (Worinkeng et al., 2013). An interior design study also attempted to reduce inhibition by using art techniques (Pable, 2008).

Some studies have used indirect methods to encourage sketching. One study required assignments to be sketched, and found that this increased the rate at which students reported sketching to be important (Schmidt et al., 2012). Another study used a supportive educational atmosphere and found that fostering the confidence of students tended to help them acquire sketching skills more quickly (van Passel \& Eggink, 2013).

While sketch inhibition does not seem to be addressed in engineering design, art education seems to be well aware of it and has many interventions to overcome it. Some of the most cited activities include copying drawings upside down and restricting verbal or written communication while sketching (Edwards, 1970). Design oriented texts build on these interventions with activities specific to design thinking (McKim, 1980). Many of the exercises proposed by Edwards and McKim emphasize hemisphere reversal, or activities specifically designed to induce brain activity on the right side of the brain. Activities that induce right-brained activity are known to improve creativity (Martindale, 1999).

\section{Sketching Skills and Sketch Inhibition Modules}

We embedded two modules in a university-level toy design class, building on our earlier efforts to improve creativity in the class. The first was to teach sketching skills. After evaluating this module, we found that there was still some 
inhibition in the students. While the first module addresses inhibition related to a lack of skills (skill-set), other types of inhibition were still being reported by students. Consequently, we developed a second module to address personal, intellectual, social, situational, and comparative inhibition.

\subsection{Freehand Sketching Module}

To develop specific interventions for teaching freehand sketching, we worked with Jason Tennenhouse, an industrial designer, entrepreneur, and toy designer. With his help, we identified the most important skills for ideation sketching and formed them into a two-lecture workshop.

The workshop focuses on six overall concepts: tools, lines and weights, perspective, Boolean construction, context, and motion (see Figure 1). For tools, we provide each student with a blue watercolor pencil and an ultrafine/fine, dual-tip marker pen. We instruct students on how to draw straight lines in one stroke, and how to make different line weights with their tools. These colors are used because the mind tends to ignore blue when drawn over with black marker (Tennenhouse, 2012). Following this, we demonstrate simple primitives in 1, 2, and 3 point perspective, and indicate how to use construction lines to orient the primitives. This is followed by showing how complex shapes could be made by combining simple primitives, using Boolean operations. Next, we demonstrate

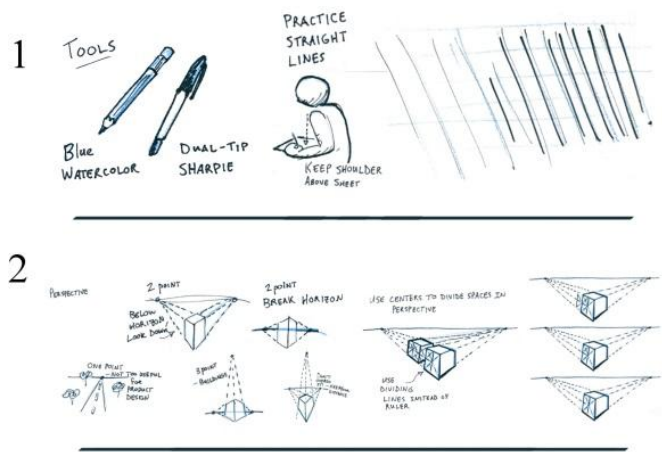

3

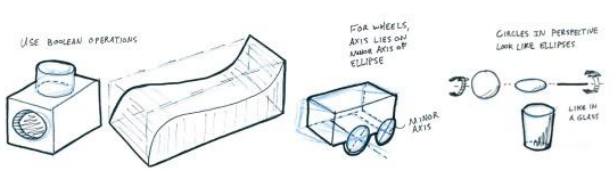

4

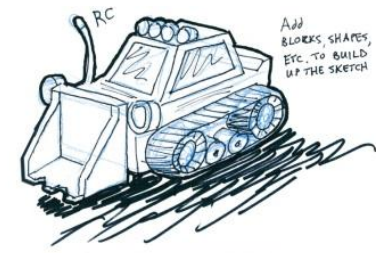

5

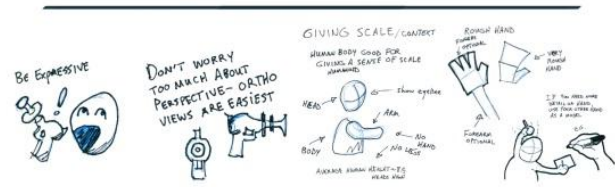

6

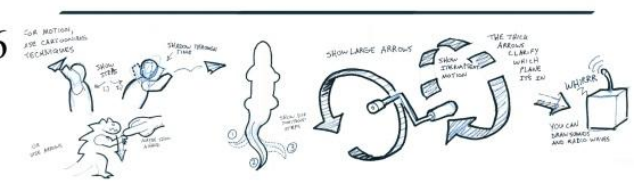

Figure 1: Concepts taught in the sketching skills lecture: 1) tools, posture, lines; 2) perspective; 3) Boolean construction of primitives into complex shapes; 4) an example of a 
complex shape made from primitives and line width; 5) context and tips; and 6) showing motion and stages

how to make simple contextual cues to indicate abstract ideas such as relative size or interaction with a user. Finally, we show how to draw unambiguous motion arrows, different strategies for showing stages or motion, and how to annotate a sketch. Examples are given to the students and they are asked to use these skills in a homework assignment. Students are also asked to use these skills in their course projects.

\subsection{Sketch Inhibition Module}

When we observed that students were still reluctant to sketch, we recruited Scott Frankenberger, a local artist and faculty member in the art department at our university. Scott helped us identify 14 relevant techniques, commonly used

Table 1: Exercises used in the sketching inhibition-reducing activity, all times approximate

\begin{tabular}{|c|c|c|c|c|}
\hline & Exercise & Media & Purpose & Time \\
\hline 1 & Draw an animal with eyes closed & Marker Pen & $\begin{array}{l}\text { Introduce an uncomfortable } \\
\text { task }\end{array}$ & $60 \mathrm{~s}$ \\
\hline 2 & Draw a flower with opposite hand & Pencils & Brain hemisphere reversal & $60 \mathrm{~s}$ \\
\hline 3 & $\begin{array}{l}\text { Draw a self-portrait holding } \\
\text { partner's hand }\end{array}$ & Pencils & $\begin{array}{l}\text { Break social inhibition, foster } \\
\text { self-awareness }\end{array}$ & $150 \mathrm{~s}$ \\
\hline 4 & $\begin{array}{l}\text { In groups of } 4 \text {, each member draws } \\
\text { part of a house and passes to left } \\
\text { without talking }\end{array}$ & Markers & Sharing ideas with others & $200 \mathrm{~s}$ \\
\hline 5 & Draw a bicycle & Crayons & $\begin{array}{l}\text { Introduce non-technical, } \\
\text { imprecise tools }\end{array}$ & $45 \mathrm{~s}$ \\
\hline 6 & Draw a monster with finger paints & Finger paints & $\begin{array}{l}\text { Playful thinking, unexpected } \\
\text { materials }\end{array}$ & $60 \mathrm{~s}$ \\
\hline 7 & Draw mountains upside down & Finger paints & $\begin{array}{l}\text { Disorientation, hemisphere } \\
\text { reversal, unexpected materials }\end{array}$ & $90 \mathrm{~s}$ \\
\hline 8 & Draw a "sound" & Finger paints & Visualizing abstract concepts & $60 s$ \\
\hline- & Clean hands & - & $\begin{array}{l}\text { Clean up time, and breathing } \\
\text { space }\end{array}$ & $300 \mathrm{~s}$ \\
\hline 9 & $\begin{array}{l}\text { Draw the person diagonally across } \\
\text { from you } 3 \text { times - } \\
\text { quickly/fast/faster }\end{array}$ & Marker pen & $\begin{array}{l}\text { Reduce concern about details, } \\
\text { emphasize quick sketching }\end{array}$ & $100 \mathrm{~s}$ \\
\hline 10 & $\begin{array}{l}\text { Draw same thing (cat) } 3 \text { times using } \\
\text { different media each time }\end{array}$ & Various & $\begin{array}{l}\text { Revisit the same problem with } \\
\text { different resources }\end{array}$ & $90 \mathrm{~s}$ \\
\hline 11 & $\begin{array}{l}\text { Draw a house using a continuous } \\
\text { line (never lift pencil) }\end{array}$ & Pencil & Dealing with limitations & $90 \mathrm{~s}$ \\
\hline 12 & $\begin{array}{l}\text { Fill the page from the edges to the } \\
\text { middle with a vehicle for } \\
\text { transportation }\end{array}$ & Markers & $\begin{array}{l}\text { Maximizing all your resources, } \\
\text { and emphasizing the "whole" } \\
\text { picture }\end{array}$ & $45 \mathrm{~s}$ \\
\hline 13 & Draw a "sad" flower & Crayons & $\begin{array}{l}\text { Applying abstract concepts to } \\
\text { unrelated things }\end{array}$ & $45 \mathrm{~s}$ \\
\hline Prep & print submitted to Design Studies & 7 & \multicolumn{2}{|c|}{ November 12, 2015} \\
\hline
\end{tabular}


$\begin{array}{ll}\text { Scribble (marker), then find \& } & \text { Marker, } \\ \text { outline a face within the scribbles } & \begin{array}{l}\text { Pattern recognition } \\ \text { (crayons) }\end{array}\end{array}$ in art curricula to remove mental blocks to a creative session (Table 1). Some of these techniques were drawn from sketching books (Edwards, 1970; McKim, 1980). These activities help artists warm up by "loosening up" and prepare for a creative session. Each activity has a specific approach to removing mental blocks to creative flow. We implemented each of these activities in a single in lecture workshop prior to the sketching skills workshop. The workshop was taught by Scott as a guest lecture.

\section{Test 1 - Freehand Sketching Module}

We wanted to test if the interventions we introduced were effective in improving sketching skills. Our observations with the workshop led to two research questions.

- Do sketching workshops increase the quality and quantity of the sketches used by students as measured by the skills we teach?

- How does teaching sketching as a part of a design course change attitudes toward sketching and perceptions of where it fits in design?

To answer the first question, we evaluated sketches from concept generation tasks at the beginning, middle, and end of the semester. For the pre and post tests, we gave ideation homework assignments (i.e. the Mug Task, see below). For the mid-test, we used the concept generation sketches from the course design project. While we do not have a comparison group, we can be relatively certain that any observed changes are due to our intervention, since no other classes in ME teach freehand sketching skills. Unless the students had taken art classes, they had no prior exposure to the information in the workshop. 


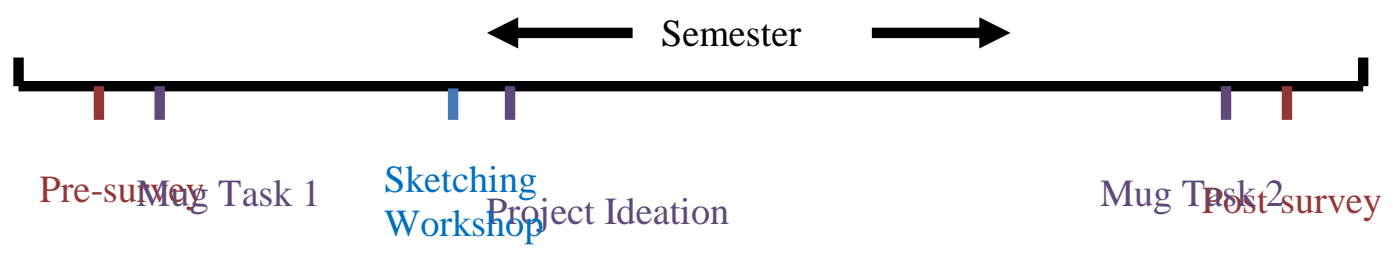

Figure 2: The order of research activities throughout the semester. Research question 1 is evaluated with the two mug tasks and the ideation session for the project. Research question 2 is evaluated with a pre and post survey.

We chose to test sketches from ideation tasks so 1) emphasis of the test was on the design, not the sketching skills, 2) each set of sketches were for the same purpose (ideation tasks), and 3) students would be encouraged to make more than one sketch. The Mug Task (pre-post sketching task) consisted of the following prompt:

Sketch a "mobile mug", which is able to move over your desktop. The mobile mug will be able to find its way on your big and messy desktop to be closer to you, and to make sure you drink your coffee before it gets cold.

\section{Restrictions:}

- There are no restrictions; you can choose any system you think is better for the mobile mug to navigate over your desktop.

- You can also add some notes to explain how your concept will work.

- Take it easy and enjoy the challenge.

- Time: 5 minutes.

To test the second research question, we conducted a pre and post online survey to measure attitudes and experience with sketching and CAD. We also asked how sketching and CAD relate to the design process. We measured this at the beginning and end of the semester to see how the sum of the workshop and class affected attitudes toward sketching. We timed the surveys to be before and after the other assessments used to answer the first question (Figure 2). 
Table 2: Metrics used to evaluate the sketches. Preferred levels are in bold.

\begin{tabular}{|c|c|c|c|c|c|}
\hline Metric & Description & $\begin{array}{l}\text { High } \\
\text { Level }\end{array}$ & Mid & $\begin{array}{l}\text { Low } \\
\text { Level }\end{array}$ & Reliability \\
\hline Tools & $\begin{array}{l}\text { Was the sketch made with both a pencil } \\
\text { and marker? }\end{array}$ & Yes & - & No & $\kappa=1.000$ \\
\hline 3D Sketches & $\begin{array}{l}\text { Did the sketch include at least one attempt } \\
\text { at a 3D image? Quality is not important. }\end{array}$ & Yes & - & No & $\kappa=0.796$ \\
\hline Annotations & $\begin{array}{l}\text { Are there annotations to clarify elements } \\
\text { in the sketch? Sketch titles do not count. }\end{array}$ & Yes & - & No & $\kappa=0.970$ \\
\hline $\begin{array}{l}\text { Indicating } \\
\text { Scale }\end{array}$ & $\begin{array}{l}\text { Is there a familiar object or dimension } \\
\text { that indicates the relative size of the } \\
\text { concept depicted in the sketch? }\end{array}$ & Yes & - & No & $\kappa=0.785$ \\
\hline $\begin{array}{l}\text { Indicating } \\
\text { Context }\end{array}$ & $\begin{array}{l}\text { Is the environment where it will be used } \\
\text { or how it will be used shown? }\end{array}$ & Yes & - & No & $\kappa=0.755$ \\
\hline $\begin{array}{l}\text { Indicating } \\
\text { Motion }\end{array}$ & $\begin{array}{l}\text { Does the sketch indicate motion, such as } \\
\text { axes of rotation, steps through time, or } \\
\text { other means? }\end{array}$ & Yes & - & No & $\kappa=0.774$ \\
\hline Sketch Size & $\begin{array}{l}\text { How much of the page does the largest } \\
\text { sketch cover? }\end{array}$ & $<100 \%$ & $<50-75 \%$ & $<25 \%$ & $\rho=0.791$ \\
\hline $\begin{array}{l}\text { Line } \\
\text { Straightness }\end{array}$ & $\begin{array}{l}\text { Was the stroke fast and fluid, or was it } \\
\text { slow and tentative? }\end{array}$ & Straight & Mixed & Wobbly & $\rho=0.492$ \\
\hline $\begin{array}{l}\text { Stroke } \\
\text { Length }\end{array}$ & $\begin{array}{l}\text { Do the strokes extend the entire length of } \\
\text { the curve? }\end{array}$ & $\begin{array}{l}\text { Entire } \\
\text { length }\end{array}$ & Long & Short & $\rho=0.560$ \\
\hline $\begin{array}{l}\text { Spread of } \\
\text { Strokes }\end{array}$ & How much do retraced lines vary? & $\begin{array}{l}\text { Spread } \\
\text { out }\end{array}$ & Bunched & $\begin{array}{l}\text { Single } \\
\text { line }\end{array}$ & $\rho=0.705$ \\
\hline $\begin{array}{l}\text { Shape } \\
\text { Accuracy }\end{array}$ & $\begin{array}{l}\text { Are the lines faithful to the intended } \\
\text { shape? }\end{array}$ & Yes & Sort of & No & $\rho=0.472$ \\
\hline
\end{tabular}

\subsection{Population for Test 1 - Fall 2012}

The population consisted of students in the elective, senior-level toy design/CAD class. Most were seniors (4th year) in mechanical and biomechanical engineering, with a few juniors (3rd year). Out of 68 students in the class, 28 are omitted due to missing data $(n=40)$. Although the study was conducted through the course, participation in surveys and permission to access the sketches were voluntary. No compensation was offered, but participants were told that the results of the research would be used to improve the class. All students in the study had been exposed to freehand drafting on isometric grid paper and CAD (Mohler, 2008), but had not been taught freestyle sketching or visual thinking in any engineering classes. Unless the students had taken art classes, they had no prior exposure to the information given in these workshops. 
Table 3: Examples of various levels of each metric

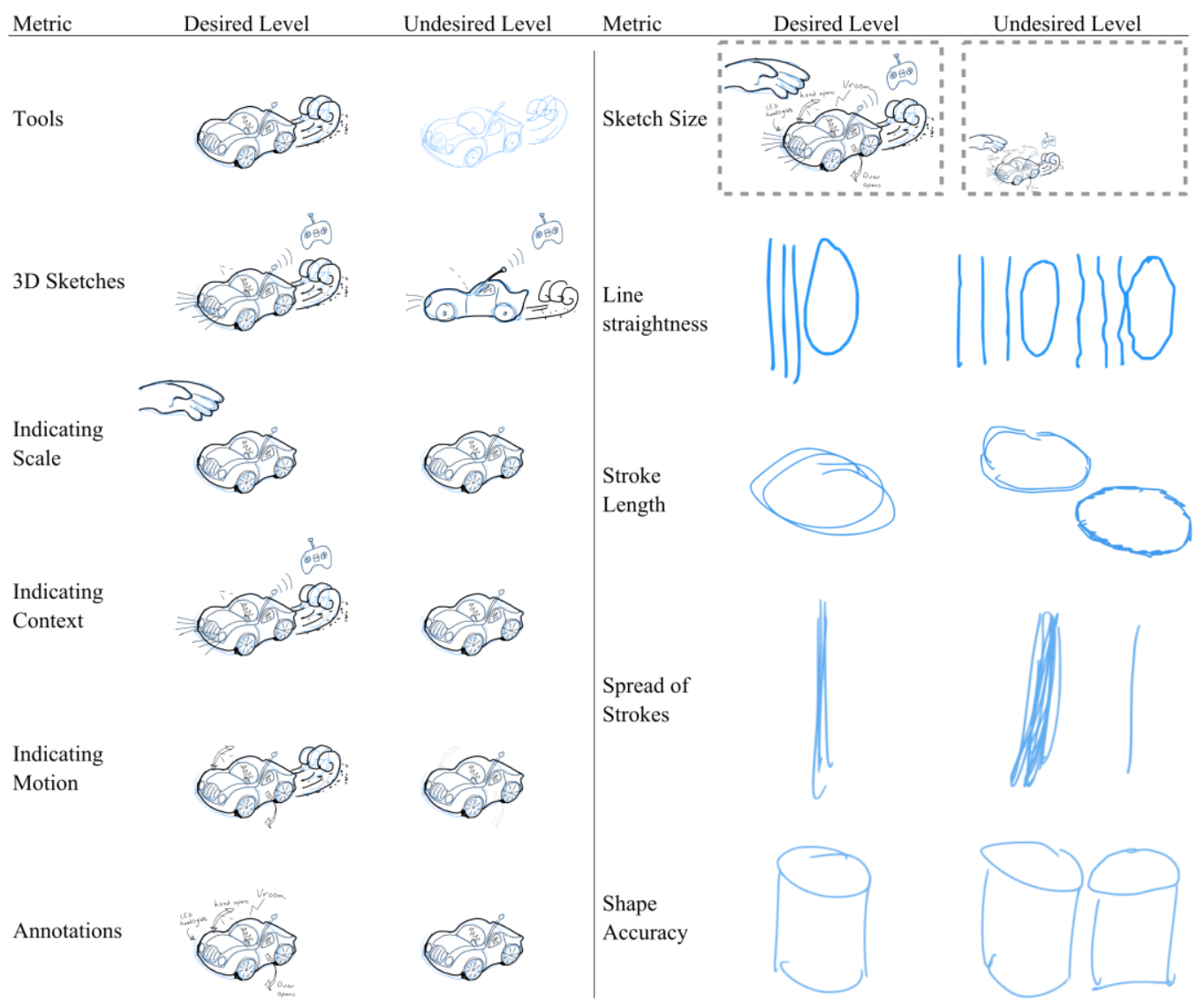

\subsection{Sketch Skills Metrics and Raters}

Instead of using typical sketch metrics which rate sketches on a scale (Joshi \& Summers, 2012), we used metrics specific to the skills we taught in our workshop. We grouped these metrics into 3 categories: style, communication, and quality. The metrics are listed in Table 2. Many of the metrics are binary (yes/no), whereas a few are along a scale. Examples of different levels of each metric can be found in Table 3 .

The sketches were analyzed by four raters. One rater is a sketching researcher, two raters are industrial design students with a strong background in art, and the last is a mechanical engineering graduate with a strong background in art and with experience with the workshops discussed in this paper. The level of agreement was calculated among each pair of raters. The pair with the highest 
Table 4: Notebook sketches. The first row is the first mug task, the second the project ideation task, and the third row the second mug task. Each column is a unique participant.

\section{Participant $1 \quad$ Participant $2 \quad$ Participant $3 \quad$ Participant 4}

Pre
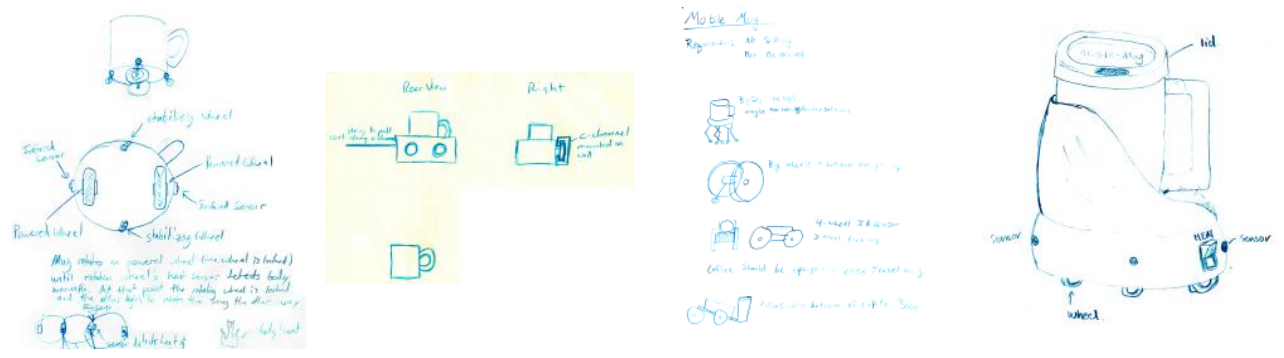

Mid
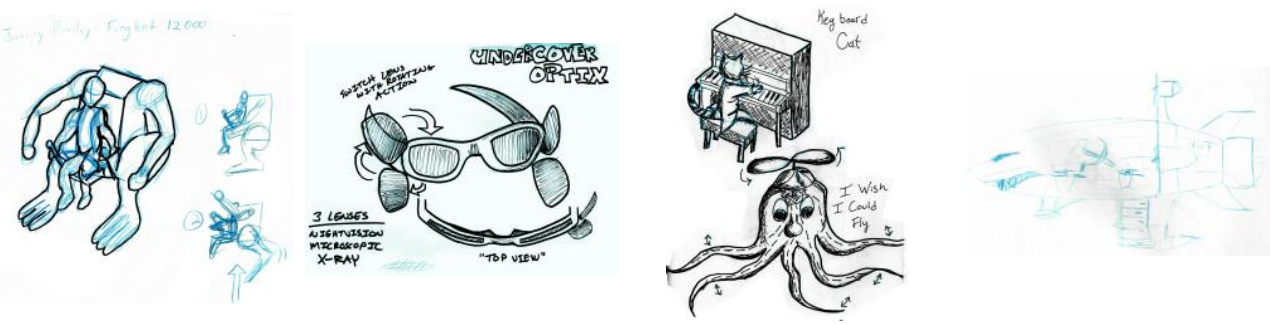

Post
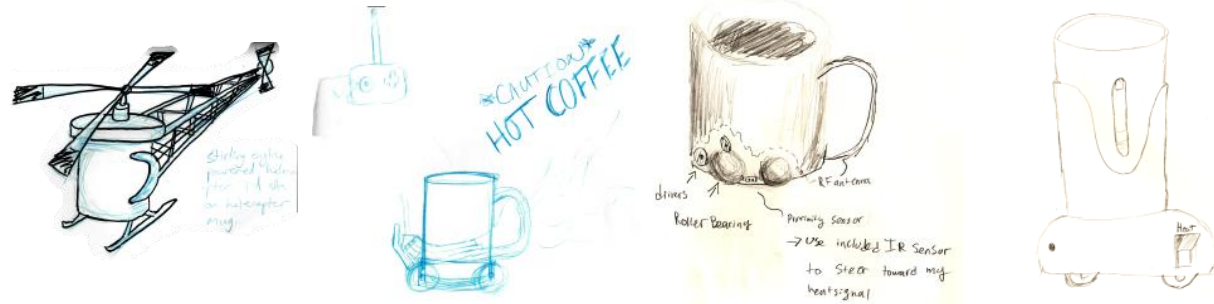

level of agreement for a particular metric was used for the analysis. In the final analysis, only two raters are used for each metric. The overall rater reliability was 0.835 using Cohen's Kappa for the binary metrics. Metrics with more than one level used ordinal scales. Accordingly, Spearman's correlation coefficient is used instead, with an average of 0.604. The majority of disagreements are systematic, which is to say that one rater is consistently one scale degree higher than the other. Disagreements were resolved by discussion between the raters.

\section{Sketching Skills Results}

We consolidated the students' assessments, design notebooks, and feedback through surveys. Examples of the sketches from the pre-test (mug task), project ideation, and post-test (mug task) can be seen in Table 4. We analyzed a total of 

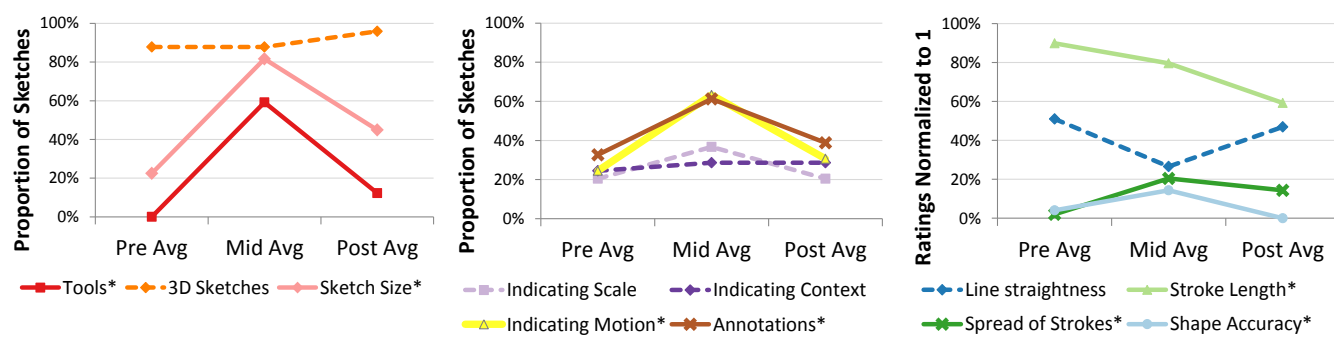

Figure 3: Values for style metrics (left), sketch quality metrics (middle), and communication-enhancing metrics (right) in the pre-mid-post tests. Significant metrics are starred and have solid lines.

Table 5: McNamar's test results for style metrics (i.e. tools and 3D sketches) and communication-enhancing metrics (i.e. annotations, scale, context, and motion)

\begin{tabular}{llcc|cccc} 
& & & 3D & & Indicate & Indicate & Indicate \\
& & Tools & Sketches & Annotations & Scale & Context & Motion \\
\hline Pretest vs. & $\chi^{2}$ & 20.00 & 0.000 & 1.920 & 2.670 & 0.290 & 15.70 \\
Midtest & $\mathrm{p}$ & $0.000^{*}$ & 1.000 & 0.267 & 0.152 & 0.791 & $0.000^{*}$ \\
Midtest vs. & $\chi^{2}$ & 21.16 & 2.670 & 3.850 & 2.910 & 0.000 & 12.80 \\
Posttest & $\mathrm{p}$ & $0.000^{*}$ & 0.219 & 0.076 & 0.134 & 1.000 & $0.000^{*}$ \\
Pretest vs. & $\chi^{2}$ & 6.000 & 2.670 & 10.71 & 0.000 & 0.330 & 0.530 \\
Posttest & $\mathrm{p}$ & $0.000^{*}$ & 0.219 & $0.001^{*}$ & 1.000 & 0.774 & 0.629
\end{tabular}

Table 6: T-test results for sketch quality metrics

\begin{tabular}{lcccccc} 
& & $\begin{array}{c}\text { Sketch } \\
\text { Size }\end{array}$ & $\begin{array}{c}\text { Line } \\
\text { Straightness }\end{array}$ & $\begin{array}{c}\text { Stroke } \\
\text { Length }\end{array}$ & $\begin{array}{c}\text { Spread of } \\
\text { Strokes }\end{array}$ & $\begin{array}{c}\text { Shape } \\
\text { Accuracy }\end{array}$ \\
\hline Pretest vs. & t & -4.000 & -3.320 & 0.680 & -8.640 & -3.40 \\
Midtest & p & $0.000^{*}$ & $0.002^{*}$ & 0.498 & $0.000^{*}$ & $0.001^{*}$ \\
Midtest vs. & $\mathrm{t}$ & 0.480 & 2.850 & 2.910 & 4.850 & 3.740 \\
Posttest & $\mathrm{p}$ & 0.633 & $0.006^{*}$ & $0.005^{*}$ & $0.000^{*}$ & $0.000^{*}$ \\
Pretest vs. & $\mathrm{t}$ & 3.490 & 0.000 & -3.730 & 3.850 & -0.660 \\
Posttest & $\mathrm{p}$ & $0.001^{*}$ & 1.000 & $0.001^{*}$ & $0.000^{*}$ & 0.511
\end{tabular}

147 sketches in Minitab at an alpha level of 0.05, and used McNamar's test for yes/no metrics and paired-samples t-tests for multi-level metrics.

\subsection{Quantitative Results}

The results are summarized in Figure 3. For the significant metrics (Tables 5 and 6 ), we see a variety of effects. We see short-term increases in use of tools, indicating motion, sketch size, and shape accuracy. Undesirable effects include the increased and then decreased use of annotations and spread of between 
repeated stroke. We also observed a decrease in stroke length and line straightness, indicating trepidation. This is probably due to new skills being taught. Another undesired effect is that many of the gains from the workshop were lost at the end of the semester. Other changes we observe are not large enough to be statistically significant.

Overall, these data seem to demonstrate the need for continual encouragement and practice in order for certain habits to stay. With regard to tool use, some students commented in their final survey that they forgot to bring their tools, which may have affected results for this metric. Certain skills, such as showing scale, showing context, and using annotations were probably not emphasized enough. The emphasis on a particular sketching style may explain this decrease, as the style we taught may be considered more of an illustrative style than a technical one. Additionally, we saw an increase in the number of construction lines used in the sketches after the workshop $(\mathrm{t}=-2.45, \mathrm{p}=0.018)$. This indicates that the way we taught perspective drawing transferred into the sketches. Since accurate perspective is an advanced skill, this probably consumed much of the attention of the students.

\subsection{Pre-Post Sketching/CAD Survey}

Overall, we observed a few changes over the semester in student perception toward sketching. We saw $65 \%$ of students reported changing their attitude toward sketching as an engineering tool. Also, 62.5\% said they would not have used the style we taught them had they not attended the lecture. Finally, 87.5\% reported that they learned new ways to use sketching. Qualitatively, students seemed to be more willing to use sketching earlier in the design process, prior to CAD (Robertson \& Radcliffe, 2009). They also seemed to recognize how sketches can be used to aid problem solving. "Before the workshop, I felt freehand sketching was just another way to show ideas and concepts, not as important as having sketches in computers. Now, I feel that it should be incorporated in every design class because of its flexibility, ease and usefulness." Another student reported, "I will now begin the design process with 


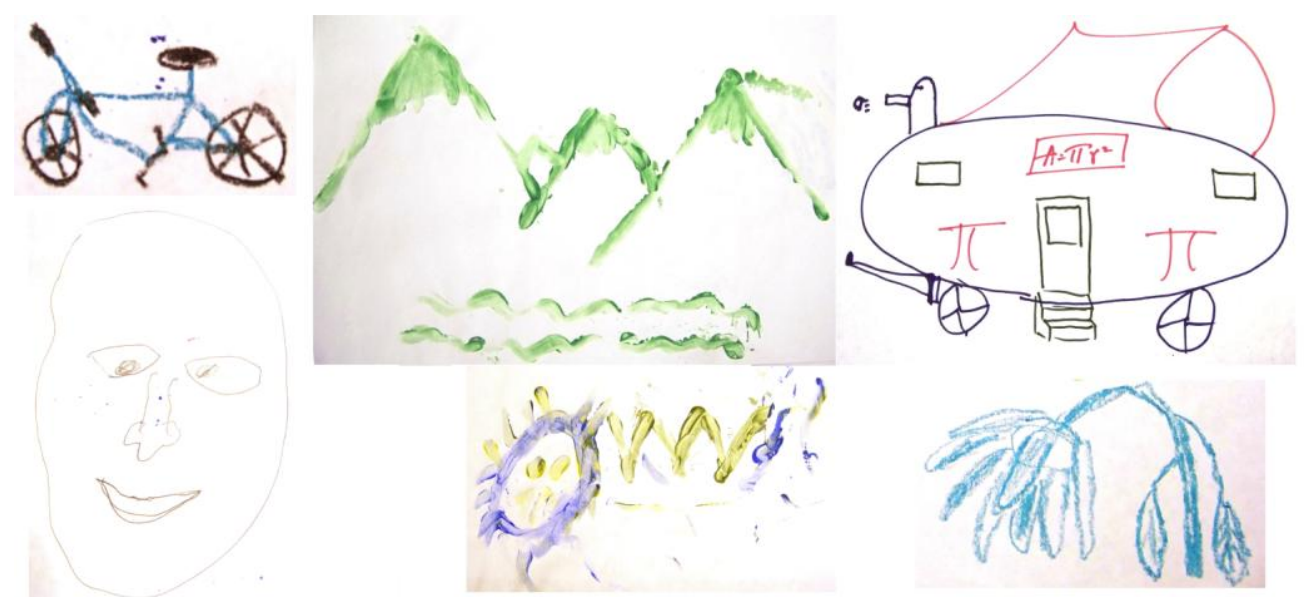

Figure 4: Examples of sketches from various students. From left to right: Top - A bicycle drawn in crayon (activity 5), mountains painted upside-down (activity 7), a house drawn by a team (activity 4); Bottom - a self-portrait drawn with a partners hand (activity 3), a monster using finger-paints (activity 6), and a sad flower (activity 14).

freehand sketching. Also, I will now produce multiple sketches instead of trying to get the design perfect on the very first sketch." The number of students who reported being comfortable with sketching did not change over the semester, however the number of students who reported being frustrated with sketching dropped from 4 to 0 .

\section{Test 2 - Sketch Inhibition Module}

We introduced the art-based interventions for reducing inhibition in a subsequent semester of the ME 444 class described above. The goal of the interventions was to remove the mental blocks to fast and effective sketching, including a belief that sketching must be high-quality to be effective. The workshop in this semester was taught by Author 1 in a single, in-class lecture. Following the inhibition-reducing workshop, we repeated the sketching skills workshop from the previous year.

A few examples of sketches from various students are shown in Figure 4. In pilot studies, $89 \%$ of the students reported liking the workshop. Many reported feeling more at ease, or feeling freer. We took this to mean the workshop was successful. However, we wanted to see the effect of the workshop over the length of the semester. 
Table 7: Sketching tasks used in the pre-mid-post tests. Task Set 1 Set 2 Mechanical Crane lifting a beam Forklift Organic Bird on a shoe Hand holding carrot Open-Ended Device to fold clothes and organize closet Device to remove leaves w/o human assistance

\begin{tabular}{lll} 
Task & Set 1 & Set 2 \\
\hline Mechanical & Crain lifting a beam & Forklift \\
Organic & Bird on a shoe & Hand holding carrot \\
Open-Ended & Device to fold clothes & Device to remove leaves \\
& and organize closet & w/o human assistance
\end{tabular}

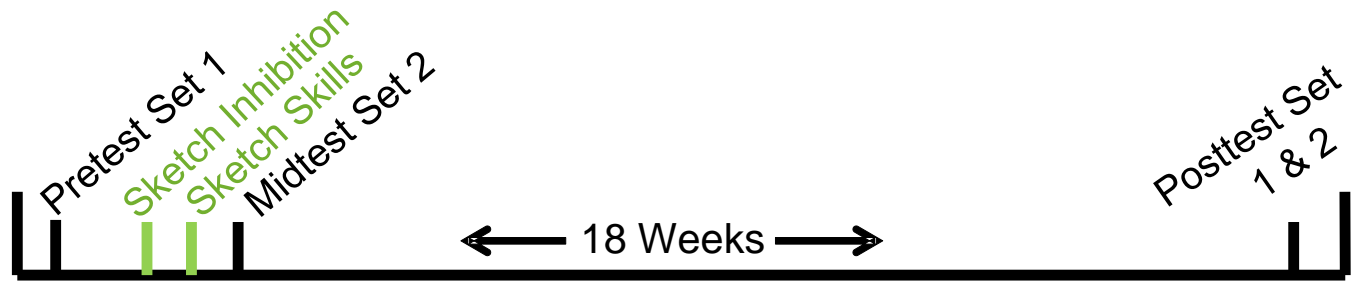

Figure 5: The order of research activities over the semester. A pretest and midtest were conducted with one of two sets of sketching tasks, and a post test was conducted with both sets of sketching tasks.

Our research questions were as follows.

- Does the workshop help students feel more comfortable with sketching?

- Does the perceived difficulty of sketching (a proxy for inhibition) reduce over the course of the semester?

To answer the first question, we distributed surveys immediately after the workshop. We asked, "What did you like/dislike about the session today?" We categorized these results by the topic of each comment. We also asked, "Have you done similar exercises at any time in you past? If yes, please supply some details (when, where, what kind of exercises)?" This second question allowed us to characterize the population better.

To measure the effect of inhibition over the semester, we used a pre-mid-post sketching exercise followed by the NASA TLX scale to measure the perceived difficulty of sketching (see Figure 5). The NASA-TLX is a qualitative tool commonly used in ergonomics and human factors research to assess the difficulty of a task, usually for operators (Proctor \& Zandt, 2008). We used this 
tool instead of creating one due to its simplicity and long-standing acceptance in the human-factors field. While the temporal and physical demand indices are not very relevant to our experiment, the mental demand, performance, effort, and frustration indices are. Since the pre and midtests were fewer than three weeks apart, we used different sets of sketching tasks to reduce a possible testing bias.

We then asked students to repeat both sets at the end of the semester. To account for different types and styles of sketching (Yang \& Cham, 2007), we constructed each test to require 3 sketches: a mechanical sketch, an organic sketch, and an open-ended sketch of something they would have to imagine. Table 7 provides more details on these tasks. The prompts for each set were chosen for similar levels of complexity and familiarity.

\subsection{Test Procedure for Question 2}

For each set of sketching tasks, we instructed students to spend no more than five minutes on each sketch. This was to ensure that the results were sketches and not drawings (Buxton, 2007). Following each sketch, students were instructed to fill out the TLX survey before moving on to the next sketch. The sketching tasks and TLX surveys were completed outside of class time. Students were informed that the sketching tasks were required as practice for the class, but the surveys were voluntary.

\subsection{Population for Test 2 - Fall 2013}

The population consisted of students in the elective, senior-level toy design/CAD class. Most were seniors (4th year) in mechanical engineering, with a few juniors (3rd year). Out of 55 students in the class, 29 are omitted due to non-participation in the post-survey. Our total sample size is $(n=26)$. Similar to the first test, participation in surveys and permission to access the sketches were voluntary. No compensation was offered, but participants were told that the

results of the research would be used to improve the class. In order to characterize the population better, we asked students after the workshop if they had experience with similar activities. If they had, we requested they provide 
details of what and when. Of the 44 who responded, $28(63 \%)$ reported they had never seen these activities before and 16 responded that they had. Only 4 gave additional details. Two said they had prior experience with these kinds of activities in high school, and the other two said they had done these activities in kindergarten.

Table 8: Pre-analysis of TLX results: The differences between Set 1 and Set 2 for the posttest, by sketch type and TLX response, and the average error for each sketch type. MD $=$ mental demand, $\mathrm{PD}=$ physical demand, $\mathrm{TD}=$ temporal demand, $\mathrm{PF}=$ performance, $\mathrm{EF}=$ effort, FR = frustration

\begin{tabular}{llllllllll} 
Type & Set 1 & Set 2 & MD & PD & TD & PF & EF & FR & Avg Err \\
\hline Mech. & Crane & Forklift & 2 & 0.8 & 2 & -0.4 & 0.3 & 2 & $5.58 \%$ \\
Org. & Shoe & Carrot & 1.45 & 1.25 & 0.8 & 1.35 & 0.2 & 1.55 & $5.50 \%$ \\
Open & Clothes & Leaf & -1.75 & -0.6 & -1.45 & -1.1 & -0.3 & -0.85 & $-5.04 \%$
\end{tabular}

\section{Survey Responses from Workshop}

The survey responses from immediately after the workshop were generally positive and suggested that the students felt less inhibited. They reported that the workshop "made me feel relaxed" and it allowed "your mind [to] run free". Students also reported liking the easiness of the workshop, liking the freeness of it, and having general positive feelings such as it being "fun". In order to not bias the responses from the students, we purposely withheld the intent of the exercises. This probably influenced some of the $11 \%$ of respondents who indicated that they felt the workshop was pointless. These results were consistent between our pilot and main studies.

\section{Pre-Mid-Post TLX Results and Interpretation}

\subsection{Pre-Analysis of TLX Data}

Prior to analyzing the data, we validated that the two sketching sets (Set 1 and Set 2) are equivalent. Due to the associative property, all possible combinations of Set 1 and Set 2 are equivalent to comparing the two sets from the post test. We calculated the pairwise difference between each set with the ideal being 0 (see Table 8). Since the NASA-TLX ranges from -10 
to +10 , we calculate the error by dividing the pairwise difference by 20 . The largest error for any one metric is less than 10\%, and the average error by task is around 5\%. This indicates that the two sets of sketching tasks are reasonably equivalent.

\subsection{Analysis of TLX Data}

We used a main effects general linear model in MiniTab to determine if the differences between the pre, mid, and post tests are statistically significant. We omitted participants who did not complete all portions of the sketching task ( $\mathrm{n}=26,29$ submissions ignored). The student and the type of task (mechanical, organic, design) were used as blocking factors, and the six TLX metrics are run as separate response variables. All necessary assumptions were met for all response variables, including homogeneity of variance and normality.

Table 9: Statistical results from the general linear model with time as main factor and sketch type (mechanical, organic, open-ended) as blocking factor. MD = mental demand, $\mathrm{PD}=$ physical demand, $\mathrm{TD}=$ temporal demand, $\mathrm{PF}=$ performance, $\mathrm{EF}=$ effort, $\mathrm{FR}=$ frustration

\begin{tabular}{ccccccc} 
& \multicolumn{2}{c}{ MD } & \multicolumn{2}{c}{ PD } & \multicolumn{2}{c}{ TD } \\
& $\mathrm{F}$ & $\mathrm{p}$ & $\mathrm{F}$ & $\mathrm{p}$ & $\mathrm{F}$ & $\mathrm{p}$ \\
\hline Test & 14.39 & $<0.001$ & 5.16 & 0.007 & 0.96 & 0.385 \\
Type & 9.1 & $<0.001$ & 0.38 & 0.687 & 1.6 & 0.204 \\
& \multicolumn{2}{c}{$\mathrm{PF}$} & \multicolumn{2}{c}{$\mathrm{EF}$} & \multicolumn{2}{c}{$\mathrm{FR}$} \\
& $\mathrm{F}$ & $\mathrm{p}$ & $\mathrm{F}$ & $\mathrm{p}$ & $\mathrm{F}$ & $\mathrm{p}$ \\
\hline & & & \multicolumn{4}{c}{$<$} \\
Test & 0.93 & 0.398 & 17.98 & 0.001 & 1.49 & 0.229 \\
Type & 0.5 & 0.605 & 0.95 & 0.389 & 2.99 & 0.053
\end{tabular}

Table 10: Bonferroni groupings for mental demand, physical demand, and effort. Rows that share a letter are not significantly different.

\begin{tabular}{l|ll|ll|ll} 
& MD & \multicolumn{2}{|c|}{ PD } & \multicolumn{2}{|c}{ EF } \\
\hline Pre & A & & A & B & A & \\
Mid & A & & A & & A & \\
Post & & B & & B & & B
\end{tabular}

The test found that there were significant long-term changes in mental demand ( $\mathrm{p}<0.0001)$, physical demand $(\mathrm{p}=0.007)$, and effort $(\mathrm{p}<0.0001$, see Table 9.) 
There was also a statistical difference for the mental demand between tasks $(\mathrm{p}<$ 0.0001). To determine how the tests differed, we performed a post-hoc Bonferroni analysis. These results are summarized in Table 10. For mental demand, physical demand, and effort; there was a significant change between the mid-test and post-test. For mental demand and effort, the pre-test was also different from the post-test. The average values show a non-significant increase from the pre-test to the mid-test and a significant decrease by the end of the semester (Figure 6).

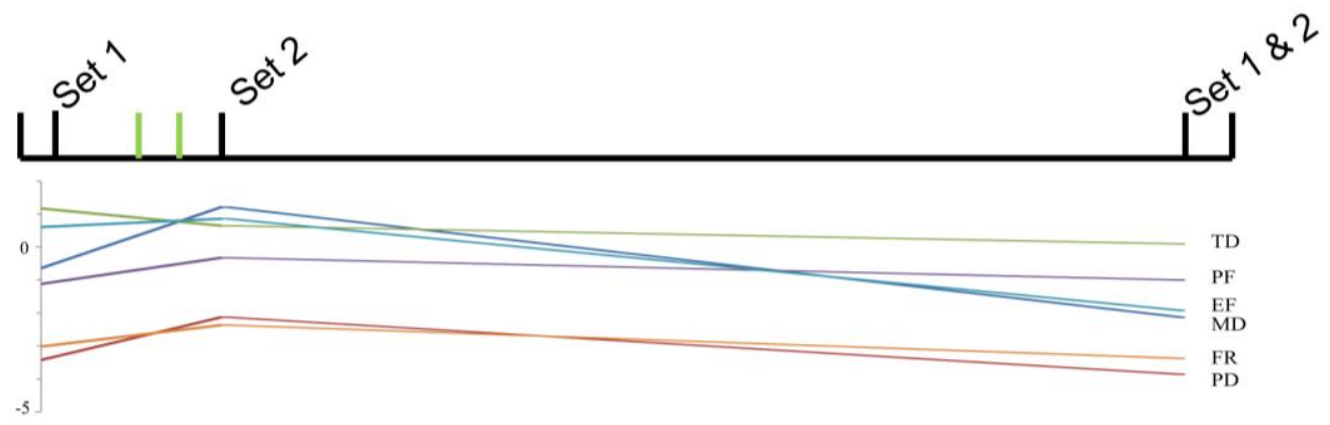

Figure 6: Average values for each of the 6 TLX measures for the semester, shown on the semester time scale. $\mathrm{MD}=$ mental demand, $\mathrm{PD}=$ physical demand, $\mathrm{TD}=$ temporal demand, $\mathrm{PF}=$ performance, $\mathrm{EF}=$ effort, $\mathrm{FR}=$ frustration

\subsection{Interpretation of TLX Results}

The TLX data do not show a decrease in inhibition immediately after the workshop. However, this conflicts with the results from the survey immediately after the inhibition workshop. In addition, the TLX data for mental demand, physical demand, and effort do show a decrease over the length of the semester.

This tells us two things. First, since mental demand and effort decreased over the semester, it appears that the encouraging environment of the class is reducing inhibition. Second, the TLX data appears to be affected by both workshops. Since both workshops occurred before the mid-test, their effects are conflated. When we designed the experiment, we did not consider that there might be an effect from the sketching skills workshop. However, we can derive the effect of the inhibition workshop from other sources. When we look at the survey results from the inhibition workshop, there is clear evidence of reduced inhibition in the words of the students. Additionally, we have preliminary work 
using brain waves as a more precise measure of mental load when performing these activities. In these preliminary studies, we found that participants who did the inhibition-reducing activities prior to concept generation had a lower cognitive workload than those that did not do a warm-up activity (Hu, 2015).

Since other sources show that the inhibition-reducing activities reduce mental workload, the TLX data tells us important details about the sketching skills workshop. The increase in mental load from the sketching skills workshop was enough to negate any short-term benefit from the inhibition workshop.

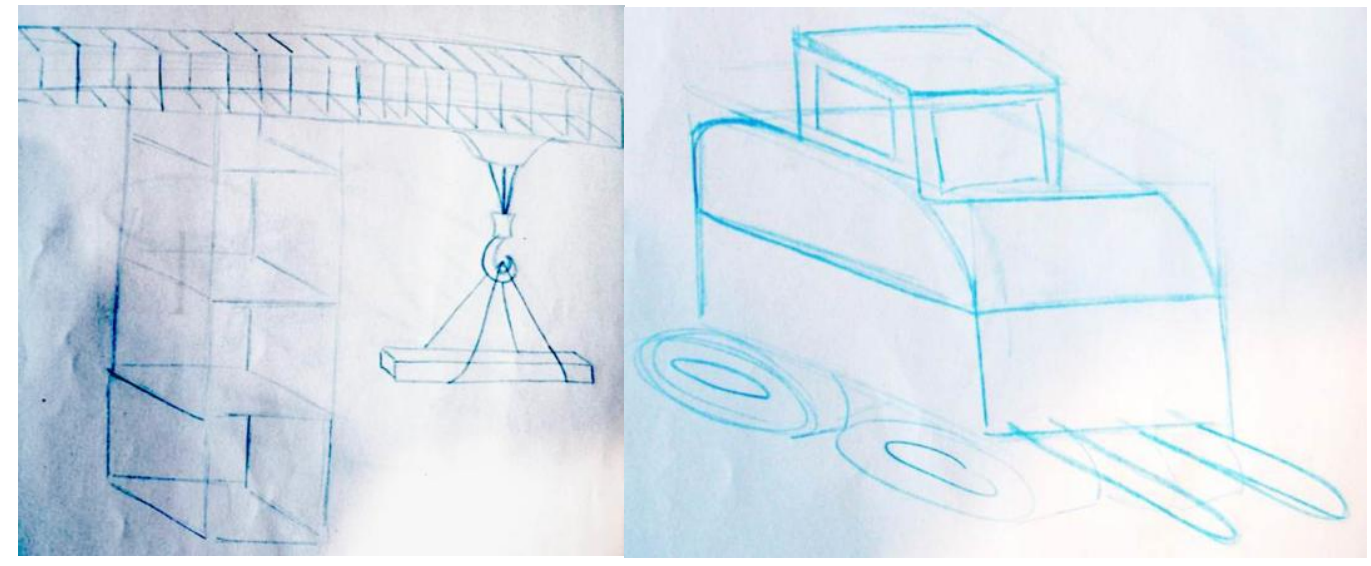

Figure 7: An example of a perspective sketch from the pretest (left) with no construction lines and no detailed connection between the tower and boom and from the midtest (right) with construction lines and Boolean construction plainly visible

To investigate this further, we compared sketches from the pre-test and midtest. We found that many of the students were incorporating elements from the sketching skills workshop in the mid-test, but not the pre-test. Figure 7 shows the pre and mid test sketches for one participant. In the pretest, the participant used perspective, but connections between the parts were unrealistic and no systematic method is discernible. In the mid-test, however, there is clear evidence of construction lines beneath the final sketched form and shapes constructed from Boolean combinations. Additionally, the wheels are drawn as ellipses, as we taught them (although the proportions in this example are not right.) These two features indicate that this student had learned and was using the skills from the sketching skills workshop. 
These results are consistent with prior literature on cognitive load. Learning new skills increases the difficulty of a task (Lawson \& Dorst, 2009) and cognitive load (Hollender et al., 2010). The skills we taught, particularly perspective were reflected in the mental demand and effort metrics.

\section{Implications and Conclusions}

In the first portion of the study, we tested with a pre-mid-post test with the sketching intervention between the pre and mid test. Over the semester, our tests showed that the use of tools, indicating motion, the sketch size and, shape accuracy improved after the workshop. However, for many metrics this effect did not last for the length of the semester. Other undesirable effects included a semester-long decrease in the number of annotations and stroke length. The decrease in stroke length is an indicator of sketch inhibition (Pable, 2008), and probably is due to feeling overwhelmed with the new content. The survey results confirmed that students felt more confident in their skills and began to view sketching in as an essential design skill. Students also reported an increased level of comfort with sketching. Overall, our results show that the students adopted many of the skills in the workshop, but they also reinforce the need for continual practice over a long period of time.

In the second portion of the study, we tested the effect of exercises for reducing inhibition to sketch using a pre-mid-post test. We found that these exercises help students feel more comfortable with sketching and more willing to use it during design. TLX data confirmed that the mental workload and perceived effort associated with sketching decreased over the semester.

The TLX data also revealed that the sketching skills workshop affects the perceived difficulty of sketching. Although students reported being less inhibited, the perceived difficulty of sketching did not decrease after the workshops. We observed that students were making use of the sketching skills workshop. From literature, we know that when students learn a new skill, cognitive load is high (Lawson \& Dorst, 2009; Hollender et al., 2010). This effect negated any decrease in cognitive load from the inhibition workshop. It 
seems from the sketches that the use of perspective may be a difficult skill for students to master, which has been historically true for artists as well.

\subsection{Recommendations}

Those who use these workshops should provide practice time and heavily emphasize context, motion, ambiguity and speed in sketching. Similarly, they should deemphasize sketch rendering and delay perspective drawing until a later date, since this increases the cognitive load. We also recommend describing how sketching affects design communication, such as talking, writing, or gestures (Linsey et al., 2011). For the sketch inhibition workshop, we recommend spreading the activities over several lectures and use them prior to concept generation. We also recommend explaining the purpose of each exercise.

\subsection{Limitations and Future Work}

This study has a few limitations. While the study has high ecological validity, more samples would provide a clearer picture of the effects that these workshops have. We had a high attrition rate on responses, probably due to low motivation at the end of the semester. Additionally, we took the TLX data in a way that conflated the effects of the two workshops. While this provided some insight on the effect of the skills workshop, it made it more difficult to determine the effect of the inhibition workshop. Future research on interventions for sketch training should explore how to gage the correct level of ambiguity for the correct phase of design, how to improve the transition between concept generation and CAD using sketches, and better methods to move from 2D to 3D sketches with minimal training. Research on sketching cognition should continue to explore inhibition. Future works should focus on better metrics for inhibition and closely examine what exercises or environments best reduce inhibition. One way to study this is using electroencephalograms (EEG) and galvanic skin responses (GSR) to measure mental load, distraction, attention, and stress directly, without relying on surveys alone. 


\section{References}

Adler, A., \& Davis, R. (2007). Speech and sketching for multimodal design. In ACM SIGGRAPH 2007 Courses SIGGRAPH '07. New York, NY, USA: $\mathrm{ACM}$.

Atman, C. J., Adams, R. S., Cardella, M. E., Turns, J., Mosborg, S., \& Saleem, J. (2007). Engineering design processes: A comparison of students and expert practitioners. J Eng Edu, October, 359-379.

Bilda, Z., Gero, J. S., \& Purcell, T. (2006). To sketch or not to sketch? That is the question. Des. Stud., 27, $587-613$.

Buxton, B. (2007). Sketching User Experiences: Getting the design right and the right design. Focal Press.

Chandrasegaran, S. K., Badam, S. K., Zhao, Z., Elmqvist, N., Kisselburgh, L. G., \& Ramani, K. (2014). Collaborative sketching with skWiki: A case study. In Proceedings of the ASME IDETC 35159.

Cross, N. (1989). Engineering design methods. Chapter 1: The Nature of Design. John Wiley \& Sons.

Cross, N. (1999). Natural intelligence in design. Des. Stud., 20, 25 - 39.

Cross, N. (2004). Expertise in design: An overview. Des. Stud., 25, 427-441.

Curran, L. C. (1988). Fauces and priapus. Retrieved Mar. 3, 2015.

Dinar, M., Shah, J. J., Cagan, J., Leifer, L., Linsey, J., Smith, S. M., \& Hernandez, N. V. (2014). Empirical studies of designer thinking: Past, present, and future. ASME J Mech Design, 137, 021101.

Duff, J., \& Ross, W. (1995). Freehand sketching for engineering design. General Engineering Series. PWS Pub. Co.

Edwards, B. (1970). Drawing on the Right Side of the Brain. J. P. Tharcher.

Eissen, K., \& Steur, R. (2011). Sketching: The Basics. BIS, Amsterdam, NL.

Farzaneh, H. H., Kaiser, M. K., \& Lindemann, U. (2012). Creative processes in groups - relating communication, cognitive processes, and solution ideas. In Proceedings of the 2nd International Conference on Design Creativity. Glasgow, UK. 
Ferguson, E. S. (1992). Engineering and the Mind's Eye volume 28. The MIT Press, Boston, MA.

Garner, S. W. (1990). Drawing and designing: the case for reappraisal. Journal of Art \& Design Education, 9, 39-55.

Goldschmidt, G. (1991). The dialectics of sketching. Creativity Research Journal, 4, 123-143.

Goldschmidt, G. (2007). To see eye to eye: the role of visual representations in building shared mental models in design teams. CoDesign, 3, 43-50.

Grenier, A. (2008). Conceptual understanding and the use of hand-sketching in mechanical engineering design. Master's thesis University of Maryland, College Park.

Hernandez, N. V., Schmidt, L. C., Kremer, G. O., \& Lin, C.-Y. (2012). An empirical study of the effectiveness of selected cognitive aids on multiple design tasks. In Proceedings of Design Computing and Cognition.

Hollender, N., Hofmann, C., Deneke, M., \& Schmitz, B. (2010). Integrating cognitive load theory and concepts of human computer interaction. Computers in Human Behavior, 26, 1278 - 1288.

Hu, W. L., Booth, J. W., Reid, T. (2015). Reducing Sketch Inhibition During Concept Generation: Psychophysiological Evidence of the Effect of Interventions. In Proceedings of ASME IDETC.

Jacobs, B. J., \& Brown, T. A. (2004). Addressing inequities in engineering sketching skills. In Proceedings of 15th AaeE Annual Convention and Conference. Toowoomba, Australia.

Joshi, S., \& Summers, J. D. (2012). Representation: Metrics for analyzing sketches: A critical survey. In Proceedings of ASME IDETC.

Kudrowitz, B., Te, P., \& Wallace, D. (2012). The influence of sketch quality on perception on product-idea creativity. AIEDAM , 26, 267-279.

Lane, D., Seery, N., \& Gordon, S. (2010). A paradigm for promoting visual synthesis through freehand sketching. Design and Technology Education, 15, $68-90$. 
Lawson, B. (2002). CAD and creativity: Does the computer really help? Leonardo, 35 .

Lawson, B., \& Dorst, K. (2009). Design expertise. Chapter 2: Understanding Design. (pp. 23-50). New York: Elsevier.

Leake, J., \& Weightman, D. (2011). Engineering and industrial design education collaboration. In ASEE Annual Conf. Exposition, AC 2011-882. Vancouver.

Linsey, J. S., Clauss, E. F., Kurtoglu, T., Murphy, J. T., Wood, K. L., \& Markman, A. B. (2011). An experimental study of group idea generation techniques: Understanding the roles of idea representation and viewing methods. ASME J Mech Design, 133, 031008.

van der Lugt, R. (2002). Brainsketching and how it differs from brainstorming. Creativity and Innovation Management, 11, 43-54.

Martindale, C. (1999). Handbook of creativity. Chapter: Biological Bases of Creativity. (pp. 140-148). Cambridge University Press.

McKim, R. (1980). Experiences in visual thinking. General Engineering Series. PWS, Boston, MA.

McKoy, F. L., Vargas-Hernandez, N., Summers, J. D., \& Shah, J. J. (2001). Influence of design representation on effectiveness of idea generation. In Proceedings of ASME IDETC.

Mohler, C., J.L. Miller (2008). Improving spatial ability with mentored sketching. Engineering Design Graphics Journal, 72, 19-27.

Oehlberg, L., Lau, K., \& Agogino, A. (2009). Tangible interactions in a digital age: medium and graphic visualizations in design journals. AIEDAM, 23, 227249.

Pable, J. (2008). In search of speed, accuracy, and student confidence: Results from two perspective sketching exercise methods. In South Regional IDETC Conference (pp. 18-24). Auburn, Alabama.

van Passel, P., \& Eggink, W. (2013). Exploring the influence of self-confidence in product sketching. In 15th International Conference on Engineering and Product Design Education: Design Education - Growing our Future. Dublin, Ireland. 
Payne, O. (2012). Op art history part i: A history of perspective in art.

Pei, E., Campbell, I., \& Evans, M. (2011). A taxonomic classification of visual design representations used by industrial designers and engineering designers. Design J, 14, 64-91.

Proctor, R. W., \& Zandt, T. V. (2008). Human Factors in Simple and Complex Systems. (2nd Ed.). New York: CRC Press.

Purcell, A., \& Gero, J. (1998). Drawings and the design process: A review of protocol studies in design and other disciplines and related research in cognitive psychology. Des. Stud., 19, 389-430.

Rattine-Flaherty, E. (2014). Participatory sketching as a tool to address students' public speaking anxiety. Communication Teacher, 28, 26-31.

Richards, J. (2013). Freehand Drawing \& Discovery: Urban Sketching and Concept Drawing for Designers. Hoboken, New Jersey: John Wiley \& Sons.

Robertson, B., \& Radcliffe, D. (2009). Impact of CAD tools on creative problem solving in engineering design. Computer Aided Design, 41, 136-146.

Computer Support for Conceptual Design. Rodgers, P. A., Green, G., \& McGown, A. (2000). Using concept sketches to track design progress. Des. Stud., 21, 451-464.

Ruocco, A., Westmoreland, S., \& Schmidt, L. C. (2009). Sketching in design: Easily influencing behavior. In Proceedings of ASME IDETC (pp. 12491256).

Schmidt, L. C., Hernandez, N. V., \& Ruocco, A. L. (2012). Research on encouraging sketching in engineering design. AIEDAM, 26, 303-315.

Schutze, M., Sachse, P., \& Romer, A. (2003). Support value of sketching in the design process. Res. Eng. Design, 14, 89-97. 10.1007/s00163-002-0028-7.

Song, S., \& Agogino, A. (2004). Insights on designers' sketching activities in product design teams. In Proceedings of ASME IDETC.

Tennenhouse, J. (2012). Personal Interview

Tovey, M., Porter, S., \& Newman, R. (2003). Sketching, concept development and automotive design. Des. Stud., 24, 135 - 153. 
Ullman, D. G. (2003). The mechanical design process. Chapter 3: Designers and Design Teams. (pp. 178-189). New York: McGraw-Hill. (4th Ed.).

Ullman, D. G., Wood, S., \& Craig, D. (1990). The importance of drawing in the mechanical design process. Computers \& Graphics, 14, 263 - 274.

Walther, J., Robertson, B., \& Radcliffe, D. (2007). Avoiding the potential negative influence of CAD tools on the formation of students' creativity. In Proceedings of the AAEE Conference.

Worinkeng, E., Summers, J. D., \& Joshi, S. (2013). Can a pre-sketching activity improve idea generation? Smart Product Engineering, (pp. 583-592).

Yang, M. C. \& Cham J. G. (2007). An Analysis of Sketching Skill and Its Role in Early Stage Engineering Design. ASME J. Mech. Design, 129 (5), 476-482.

Yang, M. C. (2009). Observations on concept generation and sketching in engineering design. Res. Eng. Design, 20, 1-11.

Yang, M. C. (2005). A study of prototypes, design activity, and design outcome. Des. Stud., 26, $649-669$. 


\section{Acknowledgements}

This research is partially funded by the NSF Award No.1227639 andthe Donald W. Feddersen Chair Professorship support from theSchool of Mechanical Engineering. We thank JasonTennenhouse and ScottFrankenberger for their central contributions to the sketching workshops presented in this paper. We are also grateful for the help SenthilChandrasegaran put into helping collect data. 